Article

\title{
Framework of Prediction Model for Mid- to Long-Term Performance Changes of Urban Railway Facilities Based on Performance Evaluation Reports
}

\author{
Jonghyeob Kim ${ }^{1}$, Jae-Goo Han ${ }^{1, *}$, Goune Kang ${ }^{1} \mathbb{D}$ and Kyung-Ho Chin ${ }^{2}$ \\ 1 Department of Construction Policy Research, Korea Institute of Civil Engineering and Building Technology, \\ Goyang-si 10223, Korea; jkim@kict.re.kr (J.K.); gounekang@kict.re.kr (G.K.) \\ 2 Construction Industry Promotion Department, Korea Institute of Civil Engineering and Building Technology, \\ Goyang-si 10223, Korea; khchin@kict.re.kr \\ * Correspondence: jghan@kict.re.kr
}

Citation: Kim, J.; Han, J.-G.; Kang,

G.; Chin, K.-H. Framework of

Prediction Model for Mid- to

Long-Term Performance Changes of Urban Railway Facilities Based on Performance Evaluation Reports. Sustainability 2021, 13, 13397.

https://doi.org/10.3390/su132313397

Academic Editor: Luca D’Acierno

Received: 12 November 2021

Accepted: 30 November 2021

Published: 3 December 2021

Publisher's Note: MDPI stays neutral with regard to jurisdictional claims in published maps and institutional affiliations.

Copyright: () 2021 by the authors. Licensee MDPI, Basel, Switzerland. This article is an open access article distributed under the terms and conditions of the Creative Commons Attribution (CC BY) license (https:// creativecommons.org/licenses/by/ $4.0 /)$.

\begin{abstract}
To maintain railway facilities in an appropriate state, systematic management based on midand long-term maintenance plans through future performance prediction must be carried out. To this end, it is necessary to establish and utilize a model that can predict mid- to long-term performance changes of railway facilities by predicting performance changes of individual sub-facilities. However, predicting changes in the performance of all sub-facilities can be difficult as it requires large volumes of data, and railway facilities are a collection of numerous sub-facilities. Therefore, in this study, a framework for a model that can predict mid- to long-term performance changes of railway facilities through analysis of continuously accumulated performance evaluation results is proposed. The model is a system with a series of flows that can classify performance evaluation results by individual subfacilities, predict performance changes by each sub-facility using statistical methods, and predict midto long-term performance changes of the facility. The developed framework was applied to 36,537 subfacilities comprising 12 lines of two urban railways in South Korea to illustrate the model and verify its applicability and effectiveness. This study contributes in terms of its methodology in establishing a framework for predicting mid- to long-term performance changes, providing the basis for the development of an automated model able to continuously predict performance changes of individual sub-facilities. In practical terms, it is expected that railway facility managers who allow trade-off between reliability and usability can contribute to establishing the mid- to long-term maintenance plans by utilizing the model proposed in this study, instead of subjectively building them.
\end{abstract}

Keywords: performance change; performance evaluation; urban railway; mid- to long-term; prediction model

\section{Introduction}

Preventive and regular maintenance of a facility is important for it to be maintained in a state in which it can achieve its required functions [1,2]. To this end, systematic management based on mid- to long-term maintenance plans through future performance prediction of target facilities must be carried out [3]. In particular, systematic management is essential for railway facilities as they have a large number of daily uses, many closely related to safety [4]. However, predicting changes in the performance of each sub-facilities requires large volumes of data, and railway facilities are a collection of numerous subfacilities, making it difficult to predict changes in all of their performances.

Meanwhile, in South Korea, regular performance evaluation of every railway facilities is conducted, the results being reported to the government based on the 'Railway Construction and Railway Facility Maintenance Act' [5]. The performance evaluation results include basic information on individual sub-facilities (such as, time of completion, and durability), maintenance history (such as, maintenance classification, and time point), and performance 
evaluation scores. Therefore, reorganization based on a facility breakdown structure (FBS) can accumulate performance evaluation cases for each facility's elapsed years, and a model can be derived that can predict changes in the performance index of individual sub-facilities through regression analysis. Furthermore, it is possible to construct a model that can predict changes in the overall mid- to long-term performance of target railway facilities using this approach.

To this end, this study aims to develop a framework for a model that can predict mid- to long-term performance changes of facilities through the analysis of continuously accumulated performance evaluation results. This paper proceeds in three stages: first, a literature review performed at the beginning of the study is discussed; second, the model development process is expanded upon based on setting up FBSs and its codes, developing a regression analysis model to estimate performance changes of individual sub-facilities; and third, developing a mid- to long-term performance change prediction model of railway facilities. The proposed model is illustrated using 39,834 cases from 36,537 sub-facilities of two urban railway facilities in South Korea, thereby verifying its applicability and effectiveness.

\section{Literature Review}

\subsection{Performance Evaluation and Prediction}

Facility managers must establish appropriate standards for using limited resources. Furthermore, assessing and tracking the performance of a facility for future decision making is one of the most critical tasks regarding facility management [6]. Performance evaluation is imperative for comparing and establishing strategies for improvement $[7,8]$ and is a gateway to calibrating the value of a built facility [9]. Facility performance means evaluating its efficiency and effectiveness in providing the desired services for policymakers, utility managers, and regulators [3,6]. Performance evaluation allows people to understand the impact of facility managers' decisions on its success and failure, helping people make better decisions. The process of performance assessment appraises the services of a facility to attain organizational goals and is crucial to establishing management strategies [3,10]. Decision-making related to extensions, acquisitions, and strategic change relies on inspecting the performance of a facility $[3,11]$. To this end, many studies have attempted to develop performance assessment methodologies for various facilities [12-16]. Although these studies have contributed to improving performance assessment, they tended to focus on methods to understand the current state of facilities, there being insufficient consideration for predicting the future state of facilities using past data.

In recent years, several researchers have conducted studies to predict the condition of facilities. Bu et al. [17] proposed an approach integrating four categories of deterioration for predicting long-term performance of bridges. Wellalage et al. [18] applied a MetropolisHasting algorithm-based Markov chain Monte Carlo simulation technique to calibrate the state-based Markov deterioration model of railway bridge components. Sharma et al. [19] developed a model to optimize track geometry of railway based on data. Barua et al. [20] identified the deterioration of airport runway and taxiway pavement using a gradient boosting machine. These studies are valuable to predict performance of facilities; however, they were focused on facilities with simple configuration elements, and predictions for various configurations such as entire railway facilities have not been conducted.

The limitations of previous studies denote a need for a new approach to predict performance of complex facilities such as a railway and therefore serve as a basis for this study.

\subsection{Performance Evaluation of Railway Facilities in South Korea}

In the case of South Korea, the deterioration of railway facilities-a representative social overhead capital-is becoming serious. Railway bridges and tunnels that were completed more than 30 years ago account for $38.6 \%$, and 50 years ago account for $24.2 \%$ of the total. Moreover, $37.4 \%$ of electrical and communication exceed their durability periods, indicating serious potential deterioration [5]. Accordingly, the 'Railway Construction and Railway Facility Maintenance Act' was enacted to determine necessary matters for railway facility safety — such as, systematic maintenance, securing operability, strengthening station 
management, and life cycle management. To strengthen the safety of railway facilities, this act requires the establishment of a 'Basic Plan for Maintenance of Railway Facilities' every five years, and a performance evaluation is required as a basic function.

The 'Special Act on the Safety and Maintenance of Facilities' defines performance evaluation to be 'a comprehensive evaluation of performance - such as, the structural safety, durability, and usability — of facilities required to maintain their function. Moreover, the 'Guidelines on Regular Inspection and Performance Evaluation of Railway Facilities', which stipulates the matters necessary for the implementation and procedure of performance evaluation of railway facilities, defines the concept of performance for each evaluation section. According to the guidelines, safety means 'performance to prevent casualties, damage, and loss of facilities under the requirements of railway facilities', durability means 'performance of facilities to maintain the functions required during the life span of railway facilities', and usability means 'performance to provide appropriate convenience and functionality in terms of use and demand'.

\section{Methodology: Framework of the Model}

This section elaborates on the development of the proposed performance change prediction model. Figure 1 shows the conceptional framework of the model. This model is a system with a series of flows designed to classify the performance evaluation results by individual sub-facilities, predict performance changes by facility using statistical methods, and predict the mid- to long-term performance changes of all facilities. This section describes (1) the establishment of the FBS code setting criteria for the analysis of performance evaluation results, (2) the establishment of a performance change prediction model for individual sub-facilities, and (3) the proposal of a mid- to long-term performance change prediction model for railway facilities.

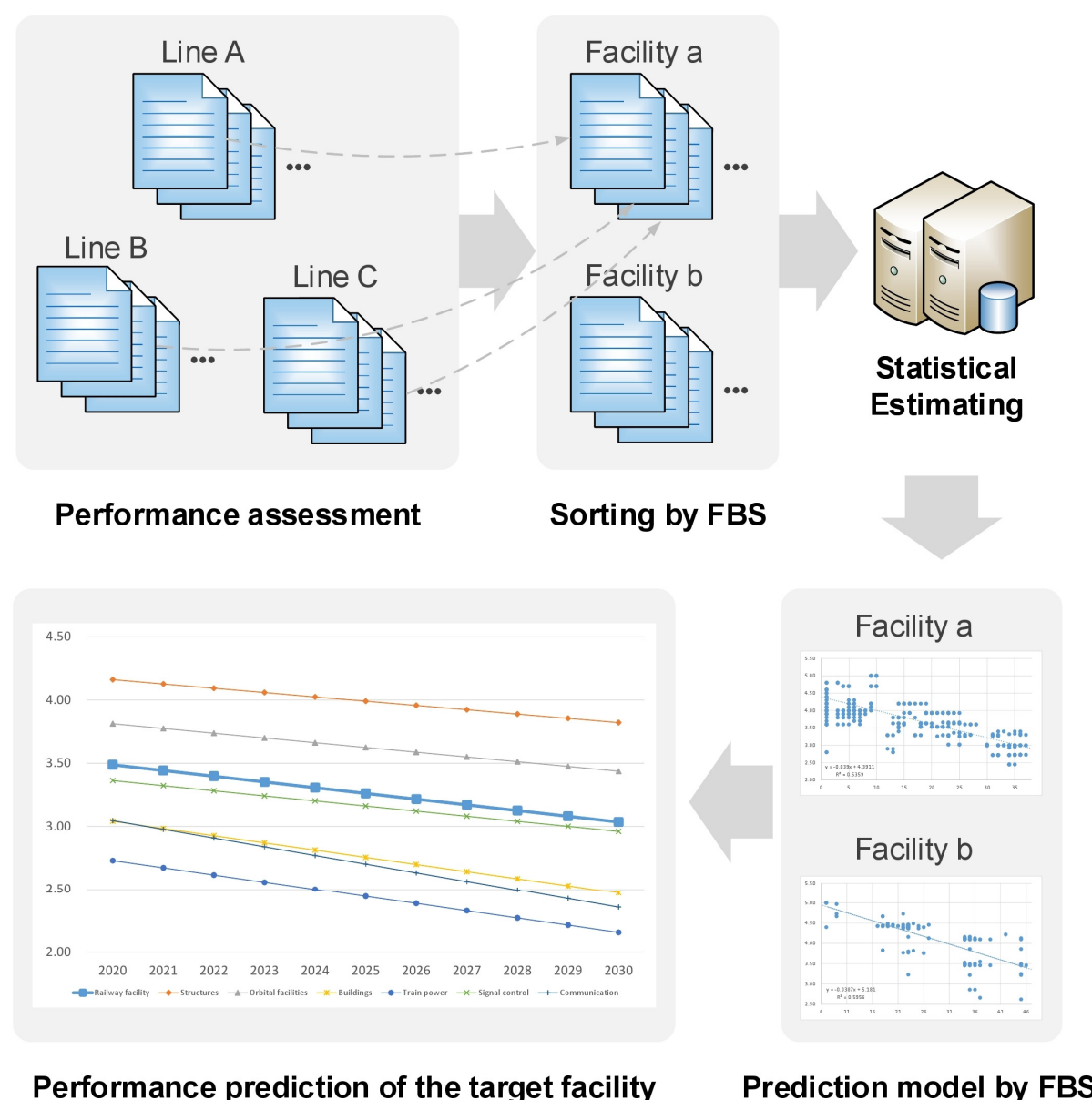

Figure 1. Conceptional framework of performance change prediction model. 


\subsection{Facility Breakdown Structure (FBS) and Its Codes}

To effectively collect and analyze cases, it is important to apply an appropriate breakdown structure [21,22]. A breakdown structure is a logical and hierarchical code containing information such as the area, location, and activity, and project tasks can be identified using the breakdown structure in modern construction project management [23]. Consequently, in this study, the FBS was established according to the facility classification and code presented in the 'Guidelines on Regular Inspection and Performance Evaluation of Railway Facilities' based on the 'Railway Construction and Railway Facility Maintenance Act'; the results of the performance evaluation of railway facilities being applied to the analysis. The FBS proposed in this study consists of $6 \times$ Level 1, $26 \times$ Level 2, $61 \times$ Level 3, and $89 \times$ Level 4 categories. Structures, orbital facilities, and buildings are classified into Level 3, and train power, signal control, and communication are classified into Level 4. Table 1 shows the FBS for structures, orbital facilities, and buildings. The rest of the FBS for train power, signal control, and communication are omitted because of the page limitations.

Table 1. The FBS for structures, orbital facilities, and buildings.

\begin{tabular}{|c|c|c|c|c|c|}
\hline & Level 1 & & Level 2 & & Level 3 \\
\hline \multirow{5}{*}{ A } & \multirow{5}{*}{ Structures } & A1 & Bridge & A11 & Type 1 bridge \\
\hline & & $\mathrm{A} 2$ & Tunnel & $\mathrm{A} 21$ & Type 1 tunnel \\
\hline & & A3 & Retaining wall & A31 & Type 2 retaining wall \\
\hline & & A7 & Platform & A74 & Platform safety door \\
\hline & & \multirow{3}{*}{ B1 } & \multirow{3}{*}{ Track } & $\mathrm{B} 11$ & Concrete track \\
\hline \multirow{8}{*}{ B } & \multirow{8}{*}{ Orbital facilities } & & & $\mathrm{B} 12$ & Ballasted track \\
\hline & & & & $\mathrm{B} 13$ & Runway \\
\hline & & \multirow{2}{*}{ B2 } & \multirow{2}{*}{ Rail } & B21 & Rail \\
\hline & & & & $\mathrm{B} 22$ & Guide rail \\
\hline & & \multirow{2}{*}{ B3 } & \multirow{2}{*}{ Turnout } & B31 & Rail-type \\
\hline & & & & B32 & L-shaped \\
\hline & & \multirow{2}{*}{ B4 } & \multirow{2}{*}{ Crosstie } & B41 & Wooden crosstie \\
\hline & & & & B42 & Concrete crosstie \\
\hline \multirow{8}{*}{$\mathrm{C}$} & \multirow{8}{*}{ Buildings } & \multirow{5}{*}{$\mathrm{C} 1$} & \multirow{5}{*}{ Station } & $\mathrm{C} 11$ & Station building \\
\hline & & & & $\mathrm{C} 12$ & Machinery and auxiliary equipment \\
\hline & & & & $\mathrm{C} 13$ & Firefighting equipment \\
\hline & & & & $\mathrm{C} 14$ & Air conditioning, heating, and ventilation equipment \\
\hline & & & & $\mathrm{C} 15$ & Elevator facilities \\
\hline & & \multirow{3}{*}{$\mathrm{C} 2$} & \multirow{3}{*}{ Buildings except for the station } & $\mathrm{C} 21$ & Buildings except for the station \\
\hline & & & & $\mathrm{C} 22$ & Machinery and auxiliary equipment \\
\hline & & & & $\mathrm{C} 23$ & Air conditioning, heating, and ventilation equipment \\
\hline
\end{tabular}

Unique codes were assigned to individual sub-facilities, and performance evaluation results were collected according to the codes. The codes were largely classified into route, facility, and evaluation information, as shown in Figure 2. The items that were not applicable in the code system were processed by entering "0." For example, the code 1117012F7201002 means city A (1), line 1 (1), station $\triangle \triangle(17)$, mainline (0), between stations (1), main upward line (2), disposable ticket machine (F7201), and second facility (002).

\begin{tabular}{|c|c|c|c|c|c|c|c|c|c|c|c|c|c|c|c|c|c|}
\hline \multirow{3}{*}{$\begin{array}{l}\text { Code Name } \\
\text { Digit Number }\end{array}$} & \multicolumn{7}{|c|}{ Route } & \multicolumn{8}{|c|}{ Facility } & \multicolumn{2}{|c|}{ Evaluation } \\
\hline & \multirow{2}{*}{$\begin{array}{c}\text { City } \\
1\end{array}$} & \multirow{2}{*}{$\begin{array}{c}\text { Line } \\
2\end{array}$} & \multicolumn{2}{|c|}{ Station } & \multirow{2}{*}{$\begin{array}{c}\text { Branch } \\
\text { line } \\
5\end{array}$} & Section & \multirow{2}{*}{$\begin{array}{c}\text { Track } \\
7\end{array}$} & \multicolumn{5}{|c|}{ FBS } & \multicolumn{3}{|c|}{ Order } & \multirow[t]{2}{*}{ age } & \multirow[t]{2}{*}{ Score } \\
\hline & & & 3 & 4 & & 6 & & 8 & 9 & 10 & 11 & 12 & 13 & 14 & 15 & & \\
\hline Code Number & 1 & 1 & 1 & 7 & 0 & 1 & 2 & $F$ & 7 & 2 & 0 & 1 & 0 & 0 & 2 & 13 & 2.89 \\
\hline Description & & $\begin{array}{l}\text { City A } \\
\text { betwe }\end{array}$ & sta & $\begin{array}{l}\text { statio } \\
\text { ons, r }\end{array}$ & $\begin{array}{l}\Delta, m \\
\text { upu }\end{array}$ & $\begin{array}{l}\text { line, } \\
\text { line, }\end{array}$ & & & & & & & & & & $\begin{array}{l}\text { Elap } \\
\text { evalua }\end{array}$ & $\begin{array}{l}\text { year } 13, \\
\text { score } 2.89\end{array}$ \\
\hline
\end{tabular}

Figure 2. FBS codes used in this study. 


\subsection{Performance Change Prediction by FBS (Regression Model)}

When performance evaluation of individual sub-facilities is conducted in accordance with the 'Guidelines on Regular Inspection and Performance Evaluation of Railway Facilities', the results can be organized based on the established FBS and its codes [5]. Among the results, if the statistical analysis is performed by extracting the performance evaluation result of the sub-facilities to be analyzed and the number of years elapsed at the time of evaluation, the performance change in the sub-facility based on the its elapsed years can be predicted (see Figure 3).

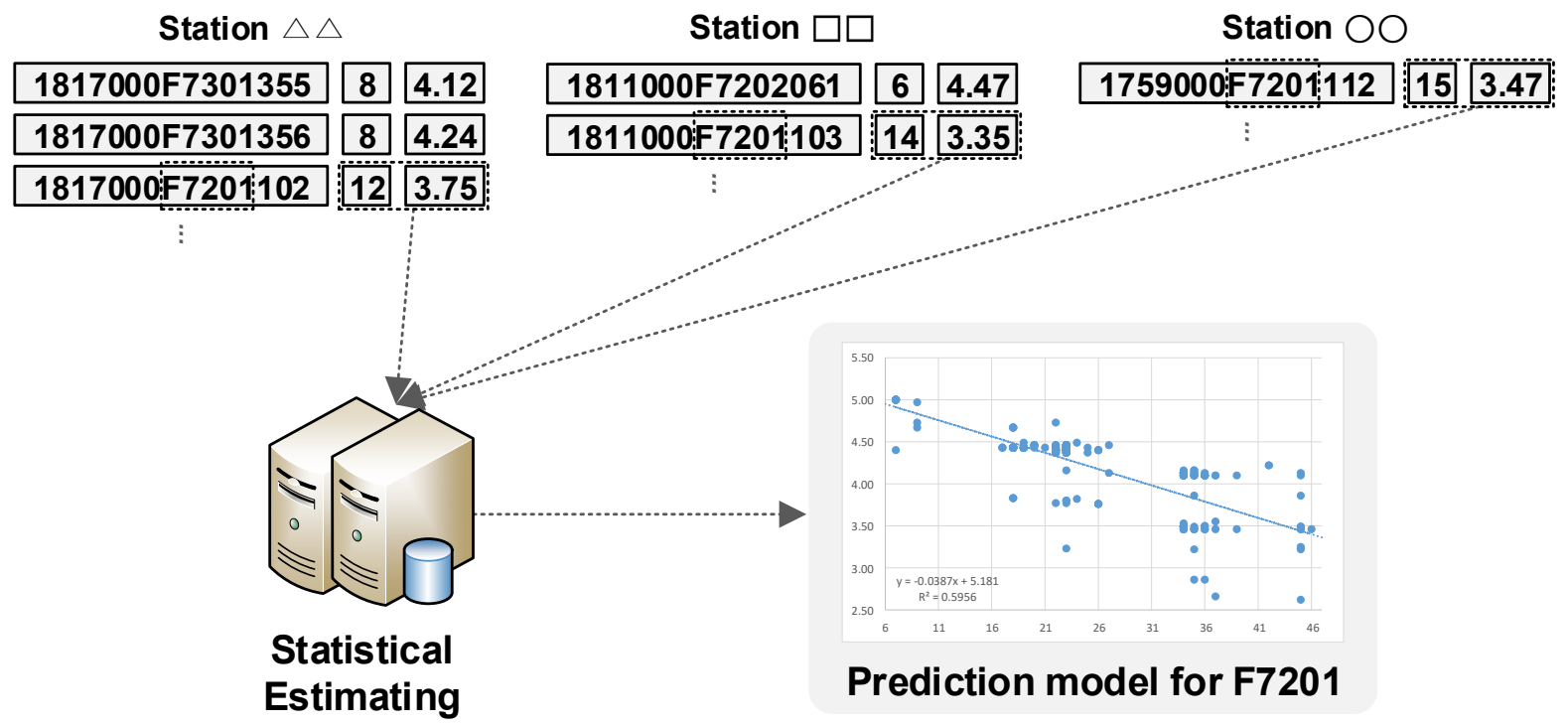

Figure 3. Concept of performance change prediction for Level 4 facilities.

In this study, a simple linear regression model was applied to predict performance changes of the sub-facilities. The model is the simplest and most basic regression model, expressing the relationship between one independent variable $\mathrm{x}$ and the dependent variable $\mathrm{y}$ in a straight line. Since it is a maximal simplification of true regression based on actual observation, it may have lower reliability compared to other types of regression models (such as multiple linear regression and nonlinear regression models). However, simple linear regression analysis was applied in this study on the basis that the variables to be analyzed were simple and that it was an effective method of increasing the usability rather than the reliability of the predictive model in the early stages of data accumulation. Thus, potential users having no alternative to prediction would utilize this model as a reference for management. Consequently, it would be essential to devise a plan to increase the reliability of the performance change prediction model for sub-facilities through follow-up studies.

Meanwhile, since railway facilities comprise a wide variety of sub-facilities, building a performance change prediction model focusing on each sub-facility may be less useful despite the relatively large time and effort required. Accordingly, this study aims to increase the usability of the early accumulation, which lacks cases, by applying a hybrid approach [24] - that is, approaching the problem from the perspective of the FBS and considering direct and indirect estimation together. An indirect estimation refers to a semistatistical method for estimating a result that does not have sufficient cases by using the cases of its higher-level classification. In a study by Kim, J. et al. [24], a hybrid approach was applied to the statistical estimation of the maintenance, repair, and replacement (MR\&R) cycle, and this study aims to utilize this concept to establish a linear regression model for predicting performance changes in facilities (see Figure 4). 


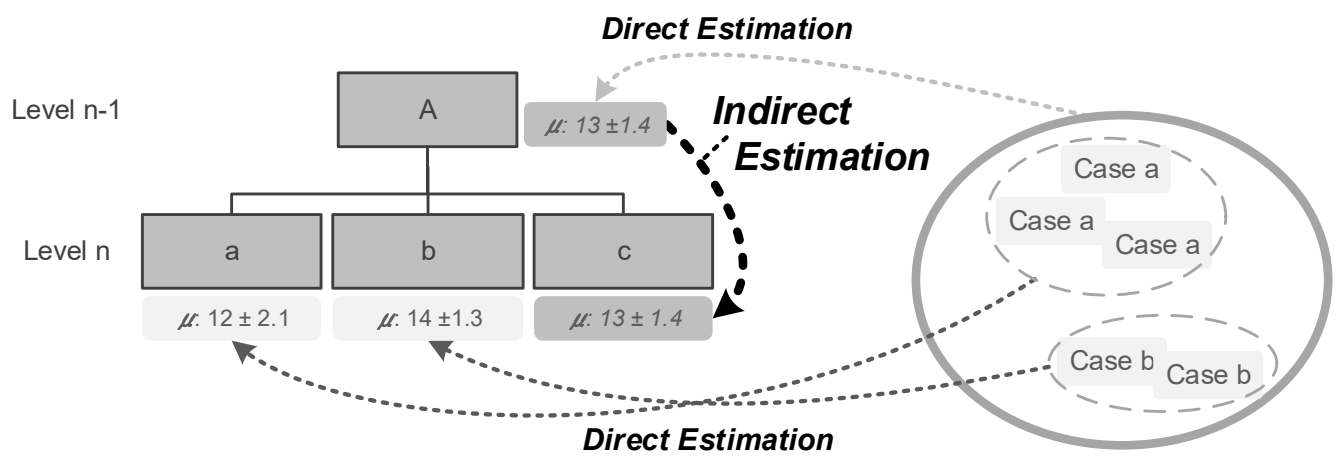

Figure 4. Concept of indirect estimation (modified from [24]).

The level of indirect estimation can be classified according to the distance from the item on which the estimation was based [24]. Indirect estimation in the above classification system can be expressed as 'Distance 1 Indirect Estimation (D1), and indirect estimation in the second and third stages of classification systems can be expressed as 'Distance 2 Indirect Estimation (D2), and 'Distance 3 Indirect Estimation (D3), respectively. Indirect estimation is a non-statistical technique and is proposed to increase the practical utilization of the DB. Therefore, when sufficient cases have been accumulated, they are replaced by statistically estimated values.

\subsection{Mid- to Long-Term Performance Change Prediction Model for Railway Facilities}

When a performance change prediction model for a facility is established, it is possible to predict the performance change based on the elapsed years of the corresponding target facility by applying it to individual sub-facilities (see Figure 5). Since performance evaluation of facilities consisting of various sub-facilities is usually conducted using a bottom-up method, the prediction will also follow the same method. Thus, the performance changes of the target railway facility can be predicted by reflecting the performance evaluation prediction results of lower-level sub-facilities from the lowest level of the FBS (structure, orbital facility, and building at Level 3 and train power, signal control, and communication at Level 4). During this process, it is necessary to reflect the importance by assigning weights when the importance of the individual FBS differs between sub-facilities. There are various weighting methodologies, including the analytic hierarchy process (AHP), Delphi, simple multi-attribute ranking technique, and ranking [25,26]. In this study, AHP was applied for assigning weights since the decision problem in this study has a hierarchical and multilevel structure with the goal of decision making on the highest level [25]. The detailed descriptions of weighting methodologies are excluded from this study.

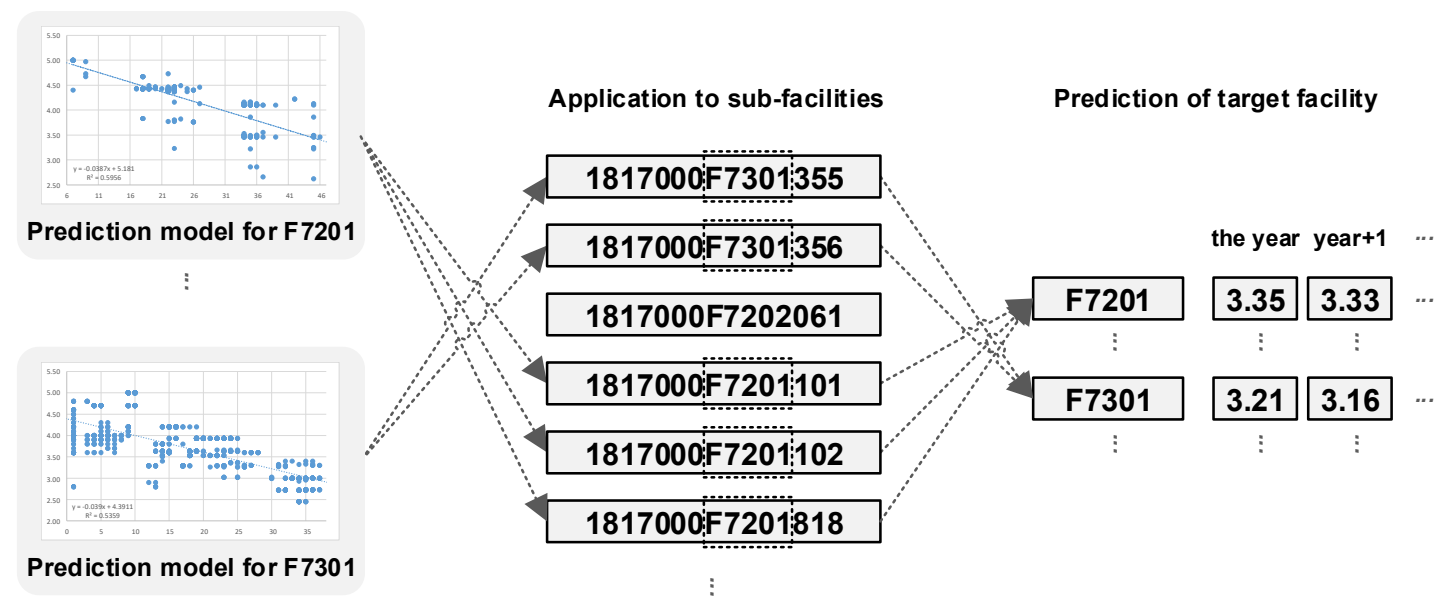

Figure 5. Concept of mid- to long-term performance change prediction of individual sub-facilities. 


\section{Illustrative Example}

To explain the developed model and verify its usability, it was applied to 36,537 subfacilities constituting 12 routes of two urban railways in South Korea. Table 2 shows detailed descriptions of the application cases. However, since the target facility was closely related to safety, information that could specify the name and location of the facility was excluded for security reasons. In addition, as the main output of this study is the framework, the illustrative example focuses on applying the framework instead of verifying linear regression models of sub-facilities. The regression models in this study were constructed to help readers understand the framework.

Table 2. Overview of application cases.

\begin{tabular}{|c|c|c|}
\hline Description & A & B \\
\hline The number of lines & 8 & 4 \\
\hline $\begin{array}{l}\text { Structures, orbital facilities, } \\
\text { buildings }\end{array}$ & 10,286 & 2715 \\
\hline $\begin{array}{l}\text { Train power, signal control, } \\
\text { communication }\end{array}$ & 17,275 & 6261 \\
\hline Total & 27,561 & 8976 \\
\hline Performance evaluation year & 2018,2020 & $2018,2019,2020$ \\
\hline The number of cases for performance evaluation & 17,146 & 22,688 \\
\hline The number of years elapsed of the case, range (year) & $2-47$ & $1-37$ \\
\hline The evaluation score of the case, range (year) & $1.50-5.00$ & $1.55-5.00$ \\
\hline Overall facility performance score in 2020 & 3.30 & 3.77 \\
\hline
\end{tabular}

The performance of railway facility A was evaluated in 2018 and 2020, and that of railway facility B in 2018, 2019, and 2020, the results being submitted in accordance with the FBS code presented above. Subsequently, a three-step process was applied to evaluate the performance of the target railway facilities. First, safety, durability, and usability were evaluated on a 5-point scale for sub-facilities; second, the evaluation results of the same lowest-level FBS were arithmetically averaged; and third, the performance scores of the upper-level sub-facilities were derived sequentially by considering the weight of each FBS. In the case application of this study, a prediction model for performance changes in sub-facilities was constructed using 39,834 performance evaluation cases that could determine performance evaluation values for each elapsed year.

As described above, a simple linear regression model was applied to predict the performance change in sub-facilities. This was a decision to expand the applicability of the prediction model. This was because if a performance change prediction model was developed using a nonlinear regression model, the elapsed years of the corresponding individual facilities would be essential when the model was applied to individual facilities, whereas the performance change prediction model developed with a simple linear regression model could predict performance changes based only on the results of the last performance evaluation and the slope value of the regression model. Table 3 shows the results of constructing performance change prediction models for sub-facilities using 39,834 data. In this study, since the FBS of structures, orbital facilities, and buildings were classified up to Level 3, prediction models of them were also established for Level 3. In the same vein, prediction models of train power, signal control, communication were established for Level 4 . Their results are omitted due to page limitations.

The weights for each FBS were derived using the AHP results obtained by the management of each railway facility. The weight (\%) of Level 1 was 0.22 for structures, 0.26 for orbital facilities, 0.08 for buildings, 0.18 for train power, 0.17 for signal control, and 0.09 for communication; Table 4 lists the Level 2 and Level 3 weights. 
Table 3. The results of the construction of a performance change prediction model for each FBS of structures, orbital facilities, and buildings.

\begin{tabular}{|c|c|c|c|c|c|}
\hline Item & Code & Slope & Intercept & R-Squared & Remark \\
\hline Type 1 bridge & A11 & -0.0592 & 4.7075 & 0.7369 & \\
\hline Type 1 tunnel & A21 & -0.0614 & 5.0362 & 0.7513 & \\
\hline Type 2 retaining wall & A31 & -0.0655 & 5.3257 & 0.7779 & \\
\hline Platform safety door & A74 & -0.0395 & 4.1538 & 0.3761 & \\
\hline Concrete track & B11 & -0.0105 & 4.0625 & 0.4255 & \\
\hline Ballasted track & B12 & -0.0117 & 4.0072 & 0.4910 & From B1 (Distance 1) \\
\hline Runway & $\mathrm{B} 13$ & -0.0117 & 4.0072 & 0.4910 & From B1 (Distance 1) \\
\hline Rail & B21 & -0.0186 & 4.0866 & 0.4914 & \\
\hline Guide rail & B22 & -0.0188 & 4.1145 & 0.5860 & From B2 (Distance 1) \\
\hline Turnout & B31 & -0.0469 & 5.0747 & 0.3962 & \\
\hline L-shaped & B32 & -0.0165 & 4.0443 & 0.6185 & From B (Distance 2) \\
\hline Wooden crosstie & B41 & -0.0120 & 3.1886 & 0.5126 & \\
\hline Concrete crosstie & B42 & -0.0153 & 3.9930 & 0.5717 & \\
\hline Station building & $\mathrm{C} 11$ & -0.0602 & 4.9056 & 0.6390 & \\
\hline Machinery and auxiliary equipment & $\mathrm{C} 12$ & -0.0559 & 4.1108 & 0.4662 & \\
\hline Firefighting equipment & C13 & -0.0347 & 3.8175 & 0.6735 & \\
\hline $\begin{array}{l}\text { Air conditioning, heating, and } \\
\text { ventilation equipment }\end{array}$ & $\mathrm{C} 14$ & -0.0336 & 3.9726 & 0.5073 & from C1 (Distance 1) \\
\hline Elevator facilities & C15 & -0.0144 & 3.6834 & 0.4531 & \\
\hline Buildings except the station & $\mathrm{C} 21$ & -0.0619 & 4.8457 & 0.7504 & \\
\hline Machinery and auxiliary equipment & $\mathrm{C} 22$ & -0.0701 & 4.7087 & 0.6110 & \\
\hline $\begin{array}{l}\text { Air conditioning, heating, and } \\
\text { ventilation equipment }\end{array}$ & $\mathrm{C} 23$ & -0.0263 & 3.8092 & 0.6030 & \\
\hline
\end{tabular}

Table 4. Weights of structures, orbital facilities, and buildings by each FBS.

\begin{tabular}{|c|c|c|c|c|c|}
\hline \multicolumn{2}{|c|}{ Level 1} & \multicolumn{2}{|c|}{ Level 2} & \multicolumn{2}{|r|}{ Level 3} \\
\hline Code & Weighting (\%) & Code & Weighting (\%) & Code & Weighting (\%) \\
\hline \multirow{6}{*}{ A } & \multirow{6}{*}{22} & A1 & 42.39 & A11 & 100 \\
\hline & & A2 & 36.96 & A21 & 100 \\
\hline & & A3 & 14.13 & A31 & 100 \\
\hline & & A7 & 6.52 & A74 & 100 \\
\hline & & Subtotal & & - & 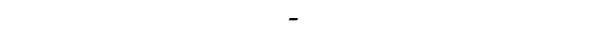 \\
\hline & & \multirow{5}{*}{ B1 } & \multirow{5}{*}{15} & B11 & 30 \\
\hline \multirow{12}{*}{ B } & \multirow{12}{*}{26} & & & B12 & 40 \\
\hline & & & & B13 & 30 \\
\hline & & & & Subtotal & 100 \\
\hline & & & & B21 & 50 \\
\hline & & \multirow[t]{3}{*}{ B2 } & \multirow[t]{3}{*}{32} & B22 & 50 \\
\hline & & & & Subtotal & 100 \\
\hline & & & & B31 & 50 \\
\hline & & \multirow[t]{3}{*}{ B3 } & \multirow[t]{3}{*}{39} & B32 & 50 \\
\hline & & & & Subtotal & 100 \\
\hline & & & & B41 & 70 \\
\hline & & \multirow[t]{2}{*}{ B4 } & \multirow[t]{2}{*}{14} & B42 & 30 \\
\hline & & & & Subtotal & 100 \\
\hline \multirow{11}{*}{$\mathrm{C}$} & \multirow{11}{*}{8} & Subtotal & \multirow[t]{2}{*}{100} & - & - \\
\hline & & & & $\mathrm{C} 11$ & 70 \\
\hline & & \multirow{5}{*}{$\mathrm{C} 1$} & \multirow{4}{*}{78} & C12 & 10 \\
\hline & & & & $\mathrm{C} 13$ & 5 \\
\hline & & & & C14 & 10 \\
\hline & & & & C15 & 5 \\
\hline & & & \multirow{4}{*}{22} & Subtotal & $\begin{array}{c}100 \\
\text { Buildingcoson }\end{array}$ \\
\hline & & \multirow{3}{*}{$\mathrm{C} 2$} & & $\mathrm{C} 22$ & $\begin{array}{l}\text { Buildings except for the station } \\
\text { Machinery and auxiliary equipment }\end{array}$ \\
\hline & & & & C23 & Air conditioning, heating, and ventilation \\
\hline & & & & Sulbtotal & equipment \\
\hline & & Subtotal & 100 & Suntolal & 100 \\
\hline
\end{tabular}


The performance changes of railway facilities A and B over the next 10 years (2021-2030) were predicted using the established performance change prediction model for each subfacility. The model was applied based on the results of the 2020 performance evaluation results of 27,561 individual facilities of railway facility A and 8976 individual facilities of railway facility B, with the prediction performance of the upper level being calculated by predicting the performance of the sub-facilities at the lowest level for each FBS and reflecting their weights.

Based on the results of the case application, it was predicted that the performance score of railway facility A would decrease by approximately 0.045 annually-that is, from 3.49 in 2020 to 3.26 in 2025 and 3.04 in 2030. Moreover, it was predicted that the performance score of railway facility B would decrease by approximately 0.036 annually - that is, from 3.77 in 2020 to 3.59 in 2025 and 3.41 in 2030. Figure 6 shows the performance change predictions of railway facilities A and B over time. In these cases, a performance level of 3.00 was set as the management objective. Thus, the maintenance managers of facility A would know that performance improvement is needed for 'buildings' and 'communication' before 2022 because their scores would be under 3.00 from that year.

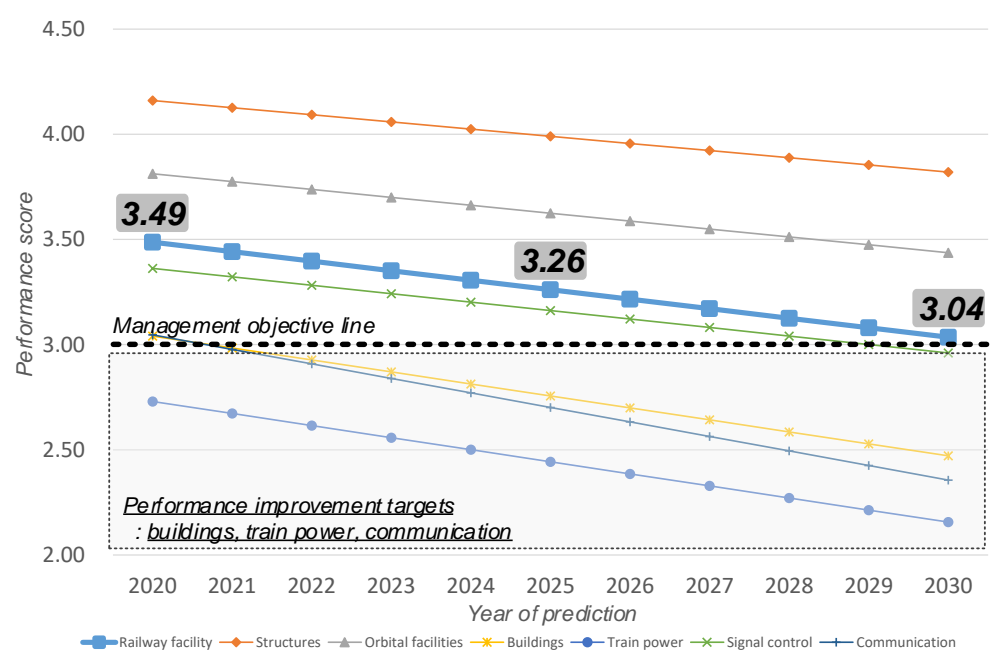

(a)

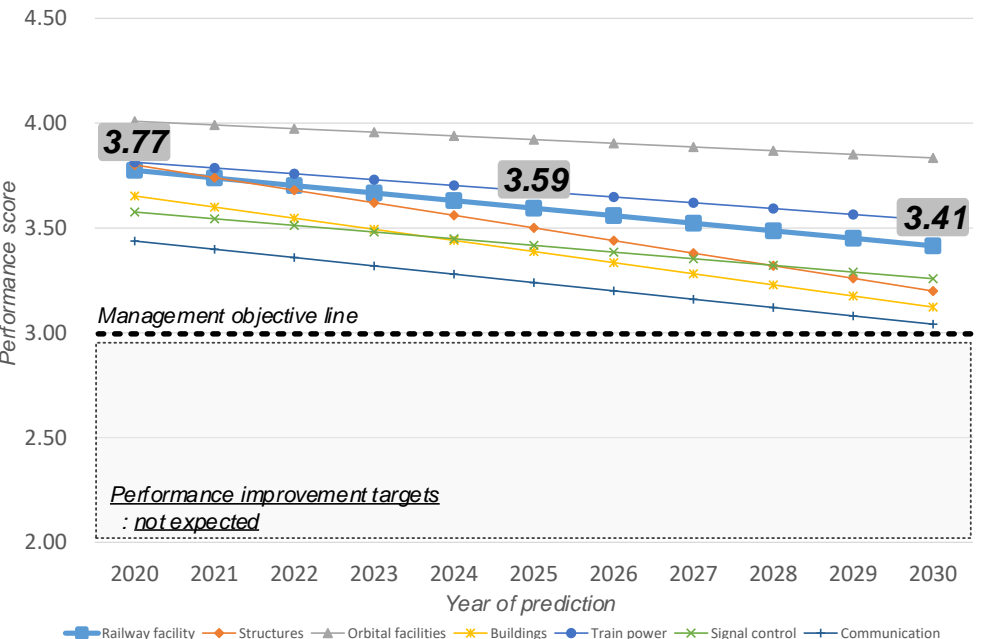

(b)

Figure 6. Mid- to long-term performance change predictions of urban railway facilities. (a) Case A. (b) Case B. 


\section{Contribution and Discussion}

In this study, a framework of a model that could predict mid- to long-term performance changes in railway facilities was established through the analysis of performance evaluation results. By the model deployment to two urban railway facilities in South Korea, it was confirmed that the proposed model could contribute to predicting mid- to long-term performance changes in urban railway facilities. The prediction model based on linear regression may seem too simple and have a deficient reliability. Thus, potential users having no alternative to prediction would utilize this model as a reference for management. However, since the elapsed years and the repair/replacement history of individual subfacilities in the case are not having been systematically managed, and where it is difficult to increase the reliability of the model in the early stages of data accumulation, a simple linear regression analysis was applied to increase the utilization. Therefore, despite the contributions of this study, it would be necessary to devise a plan to increase the reliability of the model through follow-up studies. First, it would be required to establish a system that could continuously and automatically analyze performance evaluation results. Second, to find a more suitable regression model, to research the type of regression model, and remove any outliers.

\section{Conclusions}

To maintain railway facilities in an appropriate state, systematic management based on mid- to long-term maintenance plans through future performance prediction must be carried out. To this end, it is necessary to establish and utilize a model that can predict midto long-term performance changes of target railway facilities by predicting performance changes of individual facilities. However, because predicting performance changes of facilities requires large volumes of data, and railway facilities are a collection of numerous sub-facilities, it can be difficult to predict performance changes of target facilities. To overcome this limitation, this study presented a framework of a model that could predict mid- to long-term performance changes of railway facilities through an analysis of continuously accumulated performance evaluation results of sub-facilities. In order to illustrate the model and test its applicability and usability, it was applied to 36,537 sub-facilities constituting of 12 routes of two urban railways in South Korea. The results of the illustrative example indicate that the proposed model could make a meaningful contribution to predicting the mid- to long-term performance of railway facilities.

This study's contribution is primarily in terms of its methodology for constructing a model to predict mid- to long-term performance changes, providing the basis for developing an automation model that can continuously perform predictions of performance changes in sub-facilities. In practical terms, it can contribute to improving the reliability of mid- to long-term maintenance plans by using the models developed in this study, helping railway facility managers who allows trade-off between reliability and usability move away from subjectively establishing mid- to long-term maintenance plans.

In this study, a framework was developed to propose a model to predict the performance changes of railway facilities by using the performance evaluation results of sub-facilities based on laws and regulations applied in South Korea, and a mid- to longterm maintenance prediction methodology was proposed. The proposed model based on the linear regression may seem too simple and have a deficient reliability. Thus, potential users having no alternative to prediction would utilize this model as a reference for management.

Despite of the contribution of this study, due to the lack of data accumulated to date, a performance change prediction model with a sufficiently high R-squared value for subfacilities could not be presented in this study. Therefore, for this model to be effectively used in the future, data needs to be continuously accumulated and analyzed. To this end, the authors are conducting a follow-up study to increase the reliability of predicting performance changes in sub-facilities and target facilities by developing a system that can automatically collect, analyze, and use submitted performance evaluation results. 
Author Contributions: Conceptualization, J.K.; methodology, J.K.; validation, J.K. and G.K.; formal analysis, J.K.; investigation, G.K. and J.-G.H.; resources, J.H and K.-H.C.; data curation, G.K. and J.-G.H.; writing - original draft preparation, J.K.; writing—review and editing, J.K. and J.H; visualization, J.K.; supervision, K.-H.C.; project administration, K.-H.C.; funding acquisition, K.-H.C. All authors have read and agreed to the published version of the manuscript.

Funding: This research was funded by 2021 Research Fund of Korea Institute of Civil Engineering and Building Technology grant number 20210584-001.

Conflicts of Interest: The authors declare no conflict of interest.

\section{References}

1. Kim, J.; Han, S.; Hyun, C. Minimizing fluctuation of the maintenance, repair, and rehabilitation cost profile of a building. J. Perform. Constr. Facil. 2016, 30, 04015034. [CrossRef]

2. Roper, K.O.; Payant, R.P. The Facility Management Handbook, 4th ed.; AMACOM: New York, NY, USA, 2014; ISBN 9780814432150.

3. Lavy, S.; Garcia, J.A.; Scinto, P.; Dixit, M.K. Key performance indicators for facility performance assessment: Simulation of core indicators. Constr. Manag. Econ. 2014, 32, 1183-1204. [CrossRef]

4. Koshiishi, I. Maintenance Issues for Railway Facilities and Future Prospects in Maintenance. JR East Tech. Rev. 2013, 29, 5-8.

5. Chin, K.-H.; Lee, Y.-H.; Jung, I.-S.; Kim, Y.H. A Study on Establishment of Medium and Long-Term Improvement Investment Plan of Aging National Railway Facilities; Korea Institute of Civil Engineering and Building Technology: Goyang-si, Korea, 2017.

6. Saleem, S.; Haider, H.; Hu, G.; Hewage, K.; Sadiq, R. Performance Indicators for Aquatic Centres in Canada: Identification and Selection using Fuzzy Based Methods. Sci. Total Environ. 2021, 751, 141619. [CrossRef]

7. Dejaco, M.C.; Re Cecconi, F.; Maltese, S. Key Performance Indicators for Building Condition Assessment. J. Build. Eng. 2017, 9, 17-28. [CrossRef]

8. Kincaid, D.G. Measuring Performance in Facility Management. Facilities 1994, 12, 17-20. [CrossRef]

9. Lavy, S.; Garcia, J.A.; Dixit, M.K. KPIs for facility's performance assessment, Part I: Identification and categorization of core indicators. Facilities 2014, 32, 256-274. [CrossRef]

10. Cable, J.H.; Davis, J.S. Key Performance Indicators for Federal Facilities Portfolios: Federal Facilities Council Technical Report Number 147; National Academies Press: Washington, DC, USA, 2005; ISBN 0309133521.

11. Amaratunga, D.; Baldry, D. Assessment of facilities management performance in higher education properties. Facilities 2000, 18, 293-301. [CrossRef]

12. Ata, M.; Abouhamad, M.; Hassanien Serror, M.; Marzouk, M. Data Acquisition and Structural Analysis for Bridge Deck Condition Assessment Using Ground Penetration Radar. J. Perform. Constr. Facil. 2021, 35, 04021064. [CrossRef]

13. Feroz, S.; Dabous, S.A. Uav-based remote sensing applications for bridge condition assessment. Remote Sens. 2021, 13, 1809. [CrossRef]

14. Gabr, M.A.; Rasdorf, W.; Findley, D.J.; Butler, C.J.; Bert, S.A. Comparison of Three Retaining Wall Condition Assessment Rating Systems. J. Infrastruct. Syst. 2018, 24, 04017037. [CrossRef]

15. Grigg, N.S. Condition Assessment of Water Distribution Pipes. J. Infrastruct. Syst. 2006, 12, 147-153. [CrossRef]

16. Mazumder, R.K.; Salman, A.M.; Li, Y.; Yu, X. Performance Evaluation of Water Distribution Systems and Asset Management. J. Infrastruct. Syst. 2018, 24, 03118001. [CrossRef]

17. Bu, G.P.; Lee, J.H.; Guan, H.; Loo, Y.C.; Blumenstein, M. Prediction of Long-Term Bridge Performance: Integrated Deterioration Approach with Case Studies. J. Perform. Constr. Facil. 2015, 29, 04014089. [CrossRef]

18. Wellalage, N.K.W.; Zhang, T.; Dwight, R. Calibrating Markov Chain-Based Deterioration Models for Predicting Future Conditions of Railway Bridge Elements. J. Bridg. Eng. 2015, 20, 04014060. [CrossRef]

19. Sharma, S.; Cui, Y.; He, Q.; Mohammadi, R.; Li, Z. Data-driven optimization of railway maintenance for track geometry. Transp. Res. Part C Emerg. Technol. 2018, 90, 34-58. [CrossRef]

20. Barua, L.; Zou, B.; Noruzoliaee, M.; Derrible, S. A gradient boosting approach to understanding airport runway and taxiway pavement deterioration. Int. J. Pavement Eng. 2020, 22, 1673-1687. [CrossRef]

21. Park, J.; Cai, H. WBS-based dynamic multi-dimensional BIM database for total construction as-built documentation. Autom. Constr. 2017, 77, 15-23. [CrossRef]

22. Wang, R.; Zhong, D.; Zhang, Y.; Yu, J.; Li, M. A multidimensional information model for managing construction information. J. Ind. Manag. Optim. 2015, 11, 1285-1300. [CrossRef]

23. Westney, R.E. The Engineer's Cost Handbook: Tools for Managing Project Costs, 1st ed.; CRC Press: Boca Raton, FL, USA, 1997; ISBN 9780429222191.

24. Kim, J.; Lee, H.W.; Bender, W.; Hyun, C.-T. Model for collecting replacement cycles of building components: Hybrid approach of indirect and direct estimations. J. Comput. Civ. Eng. 2018, 32, 04018051. [CrossRef]

25. Németh, B.; Molnár, A.; Bozóki, S.; Wijaya, K.; Inotai, A.; Campbell, J.D.; Kaló, Z. Comparison of weighting methods used in multicriteria decision analysis frameworks in healthcare with focus on low-and middle-income countries. J. Comp. Eff. Res. 2019, 8, 195-204. [CrossRef] [PubMed]

26. Odu, G.O. Weighting methods for multi-criteria decision making technique. J. Appl. Sci. Environ. Manag. 2019, $23,1449-1457$. [CrossRef] 